\title{
MECHATRONICS ENGINEERING EDUCATION IN REPUBLIC OF BENIN: OPPORTUNITIES AND CHALLENGES
}

\author{
Luc Djimon Clément AKONDE
}

PhD Student, State Key Laboratory of Digital Manufacturing Equipment and Technology, Mechanical school of Science \& Engineering, Huazhong University of Science and Technology, Wuhan, China

\begin{abstract}
From the traditional Mechanical engineering through Electro-mechanic to Mechatronics Engineering the main difference between them is that the last one embedded the first two at the beginning of the integrated conceptual design in the synergistic combination. This technology is based on motion control using actuators and sensors whose production has increased recently with the development of microprocessors. Even though nowadays the Mechatronics products are used worldwide, the needs and the scope of Mechatronics products vary from one country to another one. The fields of research and applied sciences for Mechatronics applications of industrialized country are different from developing country such as Republic of Benin. Since agriculture, farm work, animal breeding, livestock and fishery are among the vital sector and the potential economic power of Republic of Benin; in this paper we will discuss the opportunities and challenges of Mechatronics Education in Republic of Benin. Therefore the research is based on innovation and creativity in a multidisciplinary design concept that is able to solve the traditional problem of the primary sector which consists of: agriculture, breeding and fishing in Republic of Benin. And thus, the traditional problem of mechanization of agriculture can be solved by the Agricultural-Mechatronization or Agrotronics. Similarly, problem solving of the breeding science passes through Mechatronics technology forward Breeding-Mechatronization or Breedtronics, and the fisheries difficulty may be overcome through this emerging engineering technology, forward Fishery-Mechatronization or Fishtronics. However, opportunities are aimed at revolutionizing the primary sector and the Educational System in Republic of Benin where some significant challenges are present.
\end{abstract}

Keywords: Mechatronics, Agricultural-Mechatronization or Agrotronics, Breeding-Mechatronization or Breedtronics, Fishery-Mechatronization or Fishtronics, Educational system in Republic of Benin

\section{INTRODUCTION}

With the technological development in recent decades, new products emerged worldwide and influenced many areas of traditional engineering such as mechanical, electronics, computers, automatic control, and the related fields. The design of these new products involves hybrid performance. Varieties of industries use interdisciplinary knowledge to solve traditional engineer problems. Thereby the overproduction of industrialized countries triggered a largescale export phenomenon to the developing countries such as Republic of Benin. Most of these products are novel approach for optimal design with high performance and tend to break down barriers between mechanics, electronics, computer science and automatic. In addition, integrated sensors and actuators at the beginning of the conceptual design have revolutionized the performance and the quality of the products for the behavior of the consumers. Most of these products are simultaneously able to the mechanic, electronic, informatics and controller functions, for example airbag deployment system for automobiles, inkjet printer, read-write DVD player, Anti lock Brake System (ABS), fuel injection system of automotive motors, automatic meter money often used in banks, intelligent camera, industrial robot, domestic robot, smart machine tools, video games, automatic doors, smarts toys and so on...

Henceforth, face to the challenges of new technology in the developing countries, the barrier of communication between the traditional engineering should be broken and the intradisciplinary design work team should forward to an interdisciplinary design work team for the competitiveness and consumer welfare.

Republic of Benin needs to develop the engineering system cross-disciplinary knowledge.

It is easy to use interdisciplinary technology product but it is not obvious to define the kind of engineering this product is belonging.

What is interdisciplinary technology product?

The interdisciplinary technology product is a smart device or system engineering that involves the integration of the traditional engineering principles such as: Mechanical, Electrical, Informatics and Control, all in combination at the 
beginning of the conceptual design. This synergistic technology product is just called "Mechatronics devices or Mechatronics Engineering Applications". The keys of this emerging technology has show in Fig-1

Since 1970, the term "Mechatronics" was coined the first time in Japan [1], many definitions were published. Professor Kevin Craig [2] of Rensselaer Polytechnic Institute defined Mechatronics as "The synergistic combination of mechanical engineering, electronics, control systems, and computers. The key element in Mechatronics is the integration through design of these areas from the very beginning of the design process-no afterthought add-ons allowed."This definition points out firstly the synergistic combination of traditional engineering internship, secondly their integration at the beginning of conceptual design and thirdly additional technology is not allowed after the conceptual design stage is performed.

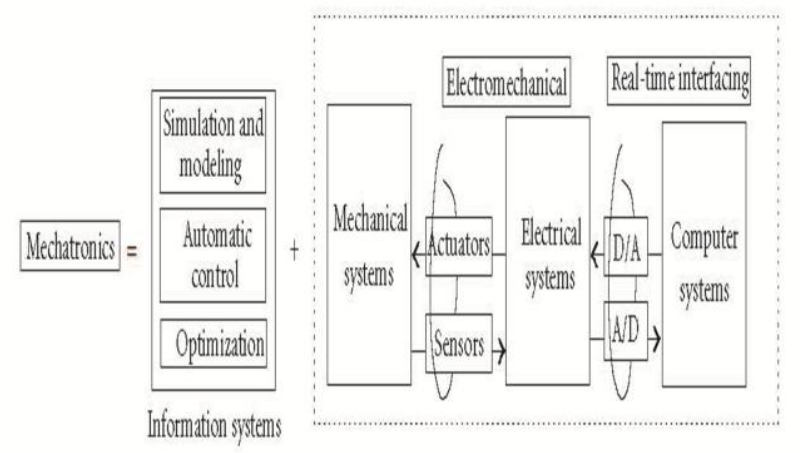

Fig-1 Mechatronics Keys Elements (Source: D.Shetty [5])

Benin imports and consumes daily "Mechatronics devices" but the neither term Mechatronics is not understood as interdisciplinary technology product. Most of the people that I asked about the definition of Mechatronics thought that I did mistake to spell the word or for those who know vaguely the term doubt about the necessity and the importance of Mechatronics in a developing country such as Republic of Benin. Someone thought Mechatronics as electro-mechanical engineering or just the science and technology which combined mechanic, electronic and informatics, leaving that confusion between the Mechatronics and Electromechanical which is two different engineering fields. This situation derives from a lack of information where my motivation to write this article comes from. A lot of people are unaware of the importance of this new technology which begat some problems such as:

- Absence of Mechatronics Engineer School

- No qualified technicians for repairing Mechatronics products.

- Limited knowledge of problem solving in traditional engineering field.
- Currently many industries are still working in traditional intra-disciplinary design work team system.

These abovementioned problems have their source in the fact that there is no national direction for scientific research in Mechatronics program which must take into account our culture, market needs, technological level of the country, our potential and economic power, natural resources and our social environment.

In order to integrate the development process of globalization in the modern world, Republic of Benin should also go forward with this new emerging engineering field by redesigning its educational program. Since the scope of Mechatronics is different from one country to another and is dependent of the market needs and economic power, Republic of Benin needs to catch Mechatronics technology to develop it primary sector, such as: traditional agricultural, animal breeding and fishing.

It would involve designing synergistic and integrated technology of different traditional engineering field at the beginning of the conceptual design. The obtained devices or Mechatronics applications will be competitive and smart agricultural tools for farming works, intelligent breeding system tools and fishing control devices. The Mechatronization of the Primary Sector can be split into three technical innovations:

- Firstly: Agro-Mechatronics or Agrotronics which can be defined as agriculture or farming work tools inspired Mechatronics system.

- Secondly: Breed-Mechatronics or Breedtronics which can be defined as breeding animals' tools inspired Mechatronics system.

- Thirdly: Fish-Mechatronics or Fishtronics which can be defined as fishing tools inspired Mechatronics system.

In this paper we describe how innovation can assist Mechatronics efficiency with the primary sector by the development of new technology and intelligent design to manufacture tools. The work focuses firstly on the perspectives and the opportunities provided by the introduction of Mechatronics Engineering Education as novel curriculum in the universities and academic research centers of Republic of Benin according to the needs of the country and secondly the challenge which the country should face.

This paper is organized as follow:

In Sect.2 we recall the brief history of Mechatronics before its description as engineering field and give the provided jobs opportunities.

Sect.3 focuses on brief description of Republic of Benin while in Sect.4 we define the Mechatronics as philosophy that scope is different from one country to another. The opportunity of Republic of Benin to go forward Mechatronization of the Primary Sector that consists of: agriculture or farm work, 
breeding and fishing method. We give brief overview to the need tools for the development of Mechatronics in Benin based on primary sector.

Sect.5 focuses on the challenges of Mechatronics Education in Republic of Benin while Sect.6 lists the Requirements. Finally this research is concluded in Sect.7.

\section{BRIEF HISTORIC OF MECHATRONICS AND}

\section{MECHATRONICS ENGINEERING}

\subsection{Brief Historic of Mechatronics}

Mechatronics was born in 1963 in Japan. A senior engineer Tetsura Mori of the company Yaskawa [3] used the term for the first time. At the beginning Mechatronics is used to describe an automatic control of electro-mechanical system. The machine and control which boast electrical actuators and sensors are capable of freely controlling mechanical arms and fingers.

Since 1980, the term becomes popular and Mechatronics information and signals system controlled computer processing unit which was designed and imbedded with the mechanical system competitive for a new product, high performance .These product may be automatic door, antilock brake system etc ..., and related innovations.

Since 1990, Mechatronics focuses on also on communication technology, wireless, GPS (Global Position System), and so on.

Nowadays, Mechatronics technology products grow quickly and are presented in any technical engineering field. Nevertheless, people have a very vague idea of what's Mechatronics (particularly in a developing country such as Republic of Benin).

Mechatronics integrates at the beginning of the conceptual design stage different technologies such as [4]: mechanic, electronic, control, informatics, communication, and signals system to overcome the difficulties arose when the design was done in a field of a single traditional technology.

\subsection{Mechatronics as Engineer Field and Job}

\section{Opportunities}

The term engineering originates from Latin word "ingeniere", which means to design or to devise. In this section we will introduce, Mechatronics as engineering field, analyze how Mechatronics engineers design the new intelligent product and discuss about the skills that new graduated are expected to have before job opportunities and career growth.

\subsubsection{Mechatronics Engineering}

Mechatronics engineering is in correlation with the classical engineering such as mechanical electrical engineering, computer science and control engineering (See Fig-2)

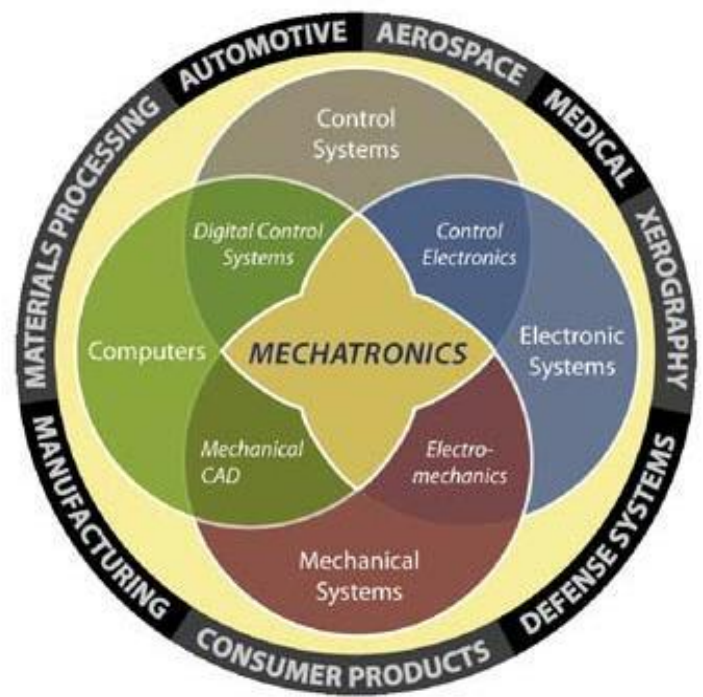

Fig -2: Mechatronics: Integrated Multidisciplinary. (Source: Rensselaer Polytechnic Institute)

This interdisciplinary engineering develops and provides optimal solutions for complex technical problems dealing with the classical engineering which usually require the interpretation of combination from classical engineering at the beginning of the conceptual design. The more increases the demand for powerful automation system, (intelligent) sensors with actuators, computer processing unit (CPU), microprocessors technologies, the more progress in Mechatronics engineering is boosted.

To satisfy these demands, several design methods have been proposed over the past year. For example Devas Shetty et al [5] confirmed that with software simulation the designer can create a plant model and then validate it against real word measurement. Once the plant model has been validated, the designer can then design the control system and optimize it until the correct response is achieve. Erkorkmaz and Y. Altinas [6] used computer numerical control (CNC) approach for high speed error control to design a Mechatronics product. H.S. Cho and M.Y.Kim [7] , introduced Opto-mechatronics technology based on a smart optical component to design a new intelligent product .This optical technology widely used in Mechatronics product design development [8,9,10-15];.emanufacturing system which allows manufacture operations for integrating the use of internet, wireless and predictive technology[16-17].In Mechatronics field the treatment of design problem often goes through stages of modeling, analysis, resolution, simulation before the representation of the prototype. 
And thus Mechatronics product has to be an integration through the combination of hardware (component) and software (information processing).

The new intelligent product result from designing on overall system includes together sensors, actuators and microcomputers into mechanical system which are simultaneously in synergistic control function [18]. The new intelligent product designed by the Mechatronics' engineer should follow the process below:

Pre study process: having a clearly idea of the product whished or wanted to design, described its main functions. A product has to be more efficient and ecological, not dangerous for human being and would operate on lower cost.

- The target market and the customer: these consist to determine the people are supposed to use the products and delimited their environment and take care about ecology.

- Next Step: The requirement list relate to the size, value quantity, type etc ...

- $\quad$ Next Step: Functional Structure

- Next Step: Solution of each function through creativity methods (brainstorming, kenead laundry)

- $\quad$ Next Step: Filtering the solution

- Next Step: Evaluating the best Solution

- Next Step: Layout Process, defining the product module, designing the whole product including mechanical, electronic, software part and the simulations is important to found errors early before the prototyping.

Finally the merit of a Mechatronics product depends on the skill of the designer to explain the product performance and quality. More details on Mechatronics design are in Fig-3.

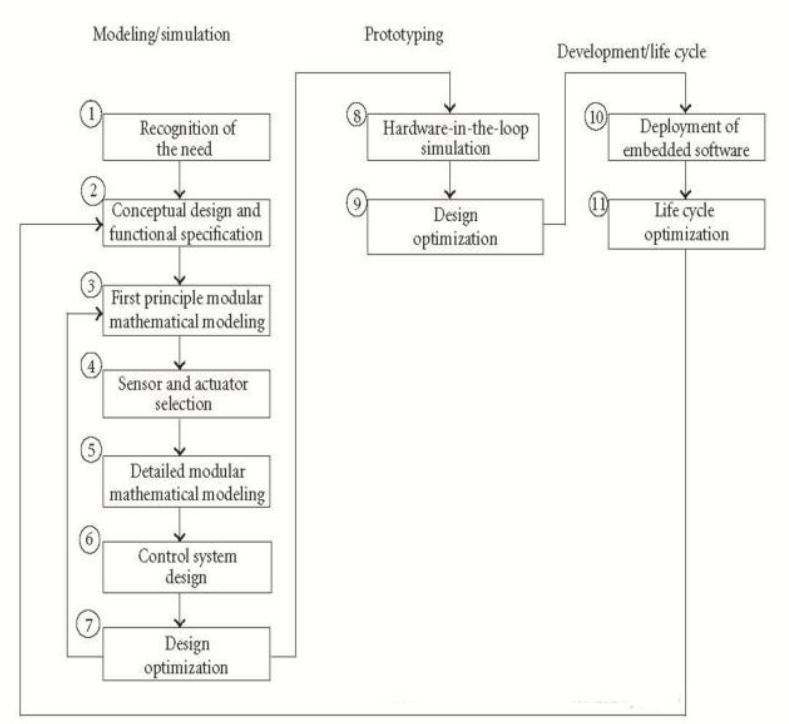

Fig-3 Mechatronics Design (Source: Devdas Shetty et al [5])

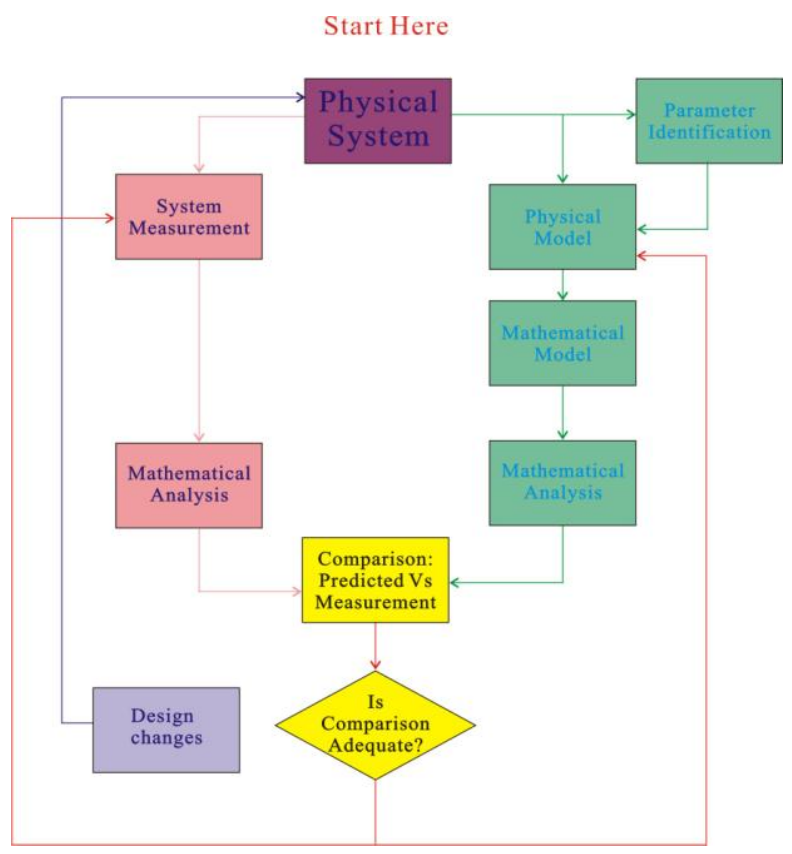

Fig-4 Mechatronics Process to Model (Source: Designed by Kevin C. Craig and Matthew A. Rosmarin) [23]

\subsubsection{Mechatronics Engineers Skills}

The value of Mechatronics engineers depends on its skill ability to communicate in the workplace, work with people, team-work, multidisciplinary group, ability to discuss and explain technical and business concepts clearly and effectively.

At each stage of product development, Mechatronics engineers work with people - tutors peers, customers, investors and vendors.

Mechatronics engineer should have the abilities to:

- Computer design and programming language skills

- $\quad$ Process to meet desired need

- Function on multidisciplinary and cultural team.

- Conduct experiment as well as analysis, interpret, measure, test and adjusts electric control, computer component, mechanical and electrical system.

- Identify, formulate and solve engineering problem.

- Communicate effectively and understand professional and ethical responsibility.

Briefly a Mechatronics engineers have to write a finale project report which describe clearly the different step of establishing the design specifications, performance, selecting and size sensors and actuators, driving system, type of CPU, interface hardware and software for the instrumentation with the component integration of the system. The Mechatronics engineers who have to complete education curriculum are able to overcome many difficulties and have abilities in creative 
solution .They can quickly get job opportunity in multidisciplinary work team. Fig-4 shows the process to compare predicted model to the measurement results.

\subsubsection{Job Opportunity}

A multidisciplinary technology, namely Mechatronics is applied to a variety of industries that include automobile , machine design, communication, medical/Para-medical, food industry, chemical process, agricultural , breeding, fishing , optical , manufacturing ,flat panel display, aerospace , pharmaceutical, robotics, etc ..., all provided job for Mechatronics engineer.

As the need for new intelligent product grown, the job opportunities grow. To be faced to the competitive challenge, companies must develop new technology then Mechatronics engineer capable of performing traditional responsibility in mechanic, electric, control and or measuring at relative level. Traditionally Mechatronics engineers have job area in multidisciplinary work team as well as in robotic industry. Additionally the job is available in all industry which can be classified in a variety of sector such as: Primary sector or extractive, secondary sector or manufacturing, and tertiary sector or service domain. [19].

The primary sector involves, the farming ,mining, fishing , breeding while the secondary sector involves the factories for processing, conversion, treatment, extracting, preserving the primary sector product, refine metal and /or processing the product from primary industry such as farm product, breeding product and fishery .The tertiary sector involves the service as teaching ,manager, research of science and technology include scientists, university, research center, and high level industry.

The Mechatronics job can vary as much as the scope of the field of Mechatronics itself, reason why, the scope of Mechatronics is different from one country to another .It's dependent of the need of each country technology level, economic power, natural resource, market needs, and social environment.

Thus it is obvious to recognize the currently needed for Mechatronics Engineering Education in Republic of Benin are clearly different from those of USA or Japan.Republic of Benin as a developing country needs medium level trained professional for now.

\section{DESCRIPTIONS OF REPUBLIC OF BENIN AND ITS EDUCATIONAL SYSTEM}

\subsection{Brief Description of Republic of Benin}

Benin economy depends basically on Agriculture, animals breeding, livestock and fishery. A tropical, sub-Saharan nation and located in West Africa, Republic of Benin extends in the north by the Republic of Niger, northwest by Burkina Faso, at the south by the Atlantic Ocean, the west by Togo and east by the Federal Republic of Nigeria. See Fig-5

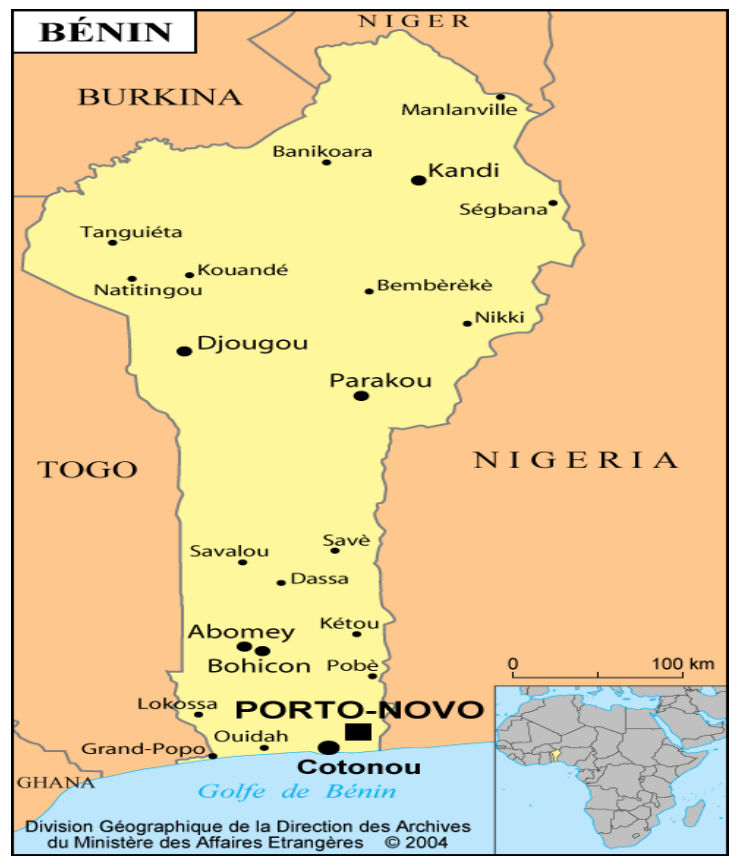

Fig-5 Map of Republic of Benin (Source Ministry of Foreign Affairs of Republic of Benin)

The capital of Benin is Porto-Novo. The country's largest economic city is Cotonou. Benin covers an area of approximately 115,500 square kilometers, with a population of approximately 10 million.

Republic of Benin has sufficient surface water. Especially in south, the rivers have fundamental role to maintain both natural and daily lives. According to estimates, the available water resources in Benin are sufficient to meet current and future demand of the both agricultural and livestock consumptions. The current water use is about $1 \%$ of the whole water resources of Benin.

The fishery sector such as aquaculture and the halieutic production are still developing in the country. However, in order to avoid or reduce the risk for the inadequate intensive and unfair fishing which impoverish our halieutic production, Republic of Benin can perform the fisheries by the novel innovation technology abovementioned: "Fishtronics"

Many projects were designed by the government to promote animal production through support to Animal Genetic Resources (AGR), veterinary duties, training courses, information, animal health, etc.... Many efforts are focused on supporting modern and traditional raising of small ruminants and dairy production. However traditional husbandry practices 
of breeding (bovine, goats, pigs and poultry) are still applying why my inspiring motivation for the "Breedtronics" for high production levels using modern and smart breeding tools.

Republic of Benin is one of Africa's largest cotton producers. Since the booming interest in bio-fuels palm oil production come back. The important cash crops produced in the country are cocoa, coffee, groundnuts and palm kernels while the fundamentals food crops are maize, cassava, sorghum, yams, millet, and beans. However no agriculture machine has been design and manufactured locally to work effectively on our soils then my inspiring motivation for the Mechatronization of our agriculture system which I called "Agrotronics"

Mineral resources such as iron ore, phosphates, chromium, rutile, clay, marble, diamonds, and limestone which are produced for use in cement manufacturing. Offshore oil and industrial diamonds are recovered for export.

One of Africa's strongest Democracies is the Republic of Benin; our official language is french but despite we have more than 200 Dialects and locals languages.

\subsection{Education System in Republic of Benin}

Major advances have been made in the national education system. Republic of Benin has abolished school fees at primary school and at secondary school for girls, and thus the recommendations of its 2007 Educational Forum are carried out [20]. In order to meet high performance to a qualitative education system for boosting the development, the public universities, institutes and research center of Republic of Benin have introduced in their curriculum many advanced varied and diversified engineering fields and disciplines[21].

The following points are the important strategies of the government to improve our education system [22]:

Democratic academic and desirable governance are established.

- Operational and innovative training programs with appropriate technological support.

- Well trained academic, administrative and technical staffs.

- The Universities and Research Institutes are positioned as centers of excellence for regional and international scientific cooperation by offering nationals and international scholarship for the students.

- A peaceful and clean environment as well as an attractive workplace has been set up.

However some constraints and challenges remain in the integrated engineering research for the design in multidisciplinary team work. Performing this will be the real bridge between our various national's laboratories and academic researches centers. The integration of multidisciplinary work team should be our currently challenge in the globalization world.

\section{OPPORTUNITIES OF THE MECHATRONIZATION OF THE PRIMARY SECTOR IN THE REPUBLIC OF BENIN}

The comparative analysis of biodiversity of the Republic of Benin shows that it has potential agricultural, pastoral, animal and fishery to support its economic development. Indeed, the practice of agriculture is distributed over the territory following areas and the relative diversity of culture depends on soil fertility.

In this section our goal is to prove:

- How Mechatronics design and manufacture in Benin can contribute to the development of primary sector and increase the productivity?

- How Mechatronics system or philosophy can create new opportunity for innovative technical solution trough the Mechatronics products?

Since the scope of Mechatronics is different from one country to another and is dependent of the need of this country according to its technology level, economic power, social environment and the market consummation, this type of engineering [Mechatronics engineering] can be though as a doctrine or philosophy. Mechatronics can be described like a tree where the roots are creativity and innovation concept of new technologies which provide local adaptation to problem solving capabilities. The trunk is a multidisciplinary environment and the branches are Mechanic engineering, Electrical engineering, Computer science and Control. The fruits are generated from the applied sciences such as: agronomy, biomedical/medical, fisheries sciences, food sciences, optics sciences, etc.

In the view of our definition, Republic of Benin needs creativity and innovation of integrated design concept technology which can provide local adaptation and adequate solution for our problems and overcome the difficulties for our agriculture system, breeding system and fishing system.

This integrated design concept which is an interdisciplinary design concept represents the philosophy of Mechatronics.

The agricultural mechanization problems in Benin can be solved by breaking the classical boundary or barrier communication between the traditional mechanic engineering and other engineering fields; we are going forward to the Agricultural Mechatronization. And thus from traditional agricultural mechanization through Mechatronics we come to Agricultural inspired Mechatronization system: AgroMechatronics or Agrotronics. 
Agrotronics product will be a modern implement as well as intelligent motorized equipment multifunctional (plough, harrow, ridger...)

Since this intelligent machine is invented locally to work effectively on our soils, they are adequate of high performance in our environment, facilities of the repair of farm implements and equipment, farmers will be able to buy cheap smart machines, spare part are available locally, multifunctional integrated design product has the ability to do automatically many works. The nature of land, topography and landscape are suitable for this novel product

Similarly animal breeding problems in Benin can be solved by breaking the classical boundary or barrier communication between the traditional breeding engineering and other engineering fields; we are going forward to the Breeding Mechatronization. And thus from traditional breeding science trough Mechatronics we come to Breeding inspired Mechatronization system: Breeding-Mechatronics or Breedtronics. Breeding sciences equipments or tools can be designed through Mechatronics philosophy for example the design and manufacture of an intelligent multifunctional poultry incubator will be useful for the poultry breeder.

In the same manners fisheries sciences problems can be solved by Fishery inspired Mechatronization system: FishingMechatronics or Fishtronics. An example is the design of a smart multifunctional fish net for controlling the quantity and the quality of the fish in the underwater.

From the three above-mentioned applied Mechatronics system we deduce, the key element of transition between traditional engineering and Mechatronics engineering is the introduction of the "concept of measurement system and the motion control technology" through the multidisciplinary program cutting across traditional engineering program. This key element is able to achieve a suitable solution problem from an optimal design of wide varieties problems. The consumers behaviors satisfaction is the fundamental goal of Mechatronics engineers .When the needed product is let out, the Mechatronics engineers are able to develop the product specification and start the product design process(See Fig3).This is possible if only if the curriculum of Mechatronics is introduced in our universities and academics research center as an engineering course :Republic of Benin should redesign its educational program according to our needs in order to come forward with this engineering field

\section{CHALLENGES OF MECHATRONICS EDUCATION IN REPUBLIC OF BENIN}

The opening of this emerging engineering field in Benin will initially devote for the training of seniors Mechatronics technicians, as a general, and then they will gradually be oriented to the specialization in Mechatronics design. They should design and fabricate prototypes inspired by
Agrotronics, Breedtronics or Fishtronics for applications in of the primary sector. For example, the manufacture of intelligent agricultural or food machinery as Agrotronics products, automatic and multifunctional Breedtronics devices to modernize the conventional breeding through innovation and the creation of modern tools and appliances such as designing an intelligent poultry incubator .Fishtronics tools as intelligent design fishing net to protect our continental waters of intense fishing pressure, improvement of our fishing production by the introduction of Mechatronics device which is able to control the $\mathrm{pH}$ of the water, and improve the productivity of our fisheries resources.

Since the development of microprocessors, software technology with smart sensors and actuators, modern innovation and new creativities revolutionalize the automatic system and challenge the traditional mechanical design.Fig-6 shows the integration of sensors -actuators.

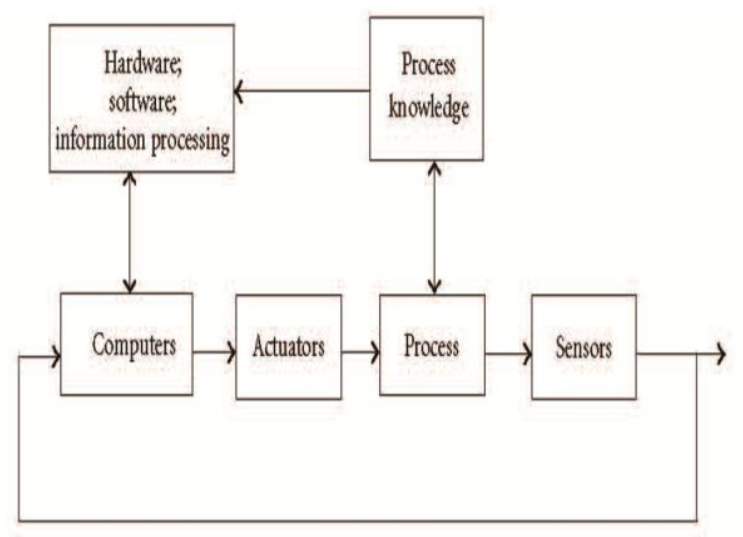

Fig-6 Sensors and Actuators integration

The main challenges of Mechatronics Education in Republic of Benin are:

- Creativity and innovation design work team for the primary sector.

- Creation of national keys research laboratories.

- These national research key laboratories should be an integrated multidisciplinary mechanical, electrical, electronic, control and computer engineering team. We should emphasize using design tool as well as simulation software.

- These national keys research laboratories projects should be in cooperation with industrial- partners.

- The industrial partners are usually the sponsors and define the project according to the need of the client or customers. The industrials partners offer an industrial training environment advantage for future Mechatronics engineer.

In order to face these challenges, Mechatronics Education involves some basic requirements and courses program 


\section{FUNDAMENTAL REQUIREMENTS COURSES IN MECHANICAL EDUCATION}

\subsection{General Courses in Engineering}

The courses and laboratory experiments are in interrelationship for Mechatronics Education. The basics modules are:

- Introduction to Mechatronics

- Measurement System and Signal Conditioning

- Sensors and Actuators Technologies

- Control and Simulation of Electro-Mechanical System

- $\quad$ Software and Computers Sciences

- Design Technology

The general framework of this emerging curriculum is presented in Fig-7.

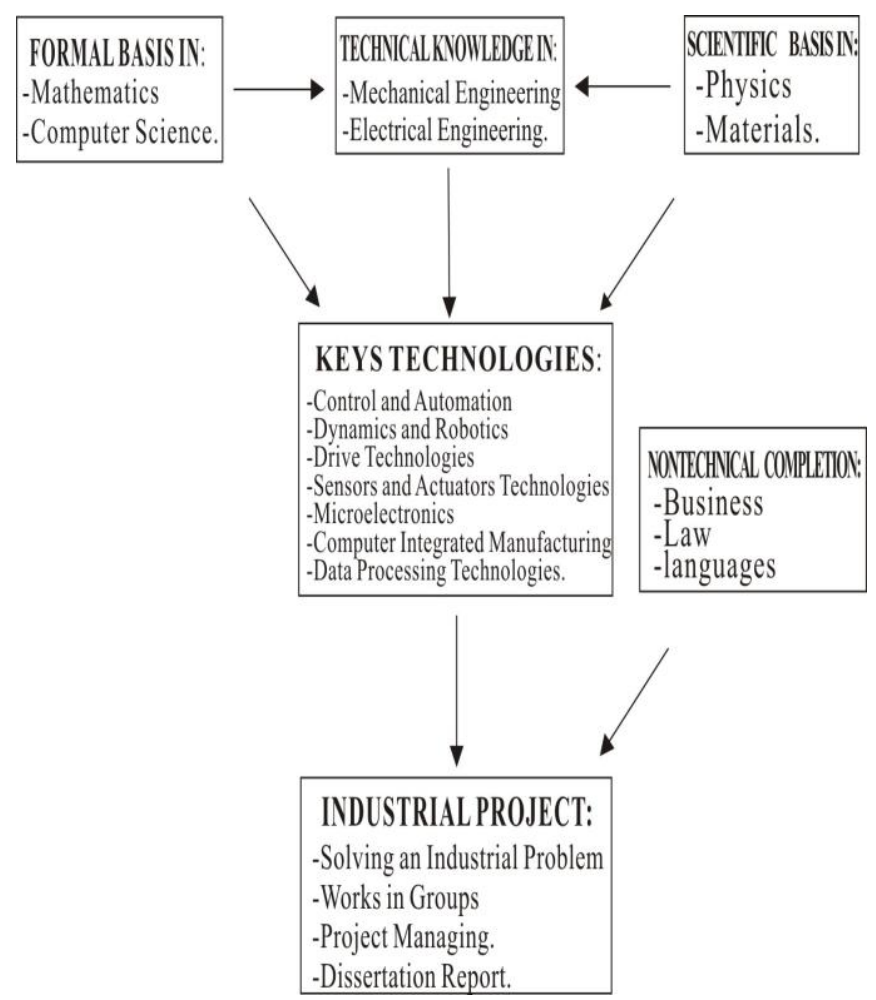

Fig-7 General Framework of Mechatronics Engineer

\subsection{Complementary Courses for Specialization in}

\section{Primary Sector}

According to our need in the primary sector the following vocational courses should be completed.

- Agronomy

- Breeding Sciences

- Fisheries Sciences

\section{CONCLUSIONS}

This research presented firstly a brief overview on Mechatronics as an emerging engineering field and it applications domains in the Republic of Benin. Secondly the work described the opportunities and challenges of Mechatronics Education in Benin before the requirements courses.

From the definition and the scope of Mechatronics we suggested that Benin should catch Mechatronics technology to develop it traditional agricultural, breeding and fishing system. The obtained results in Mechatronics applications in other countries according to their needs prove the opportunities of Benin to use Mechatronics applications for the primary sector.

In the course of solving problems the designer should know how to build a suitable model as well as strategy. The following conclusions are suggested for our study case:

The agricultural mechanization problems in Republic of Benin should be solved by the Agricultural-Mechatronics or Agrotronics.

Breeding sciences difficulties of the country can be overcome by Breeding-Mechatronics or Breedtronics.

Fishing sciences trouble may be solved by Fish-Mechatronics or Fishtronics. Additionally, this paper described the challenges of the Mechatronics Education in Republic of Benin and their requirements.

The global outlined here were both opportunities and challenges for multidisciplinary education in developing country with study case as Republic of Benin.

The biggest opportunity is that course can revolutionize not only the primary sector but also the national education system by creating real bridge between various national's laboratories and academic researches centers in different traditional engineering fields. This educational revolution will bring some significant challenges such as creativity and innovation, brain thinking. Laboratories and research centers should have a clear vision to the purpose of the integrated design. At the last but not the least low connectivity of internet network may be the principal challenge for most developing countries such as Republic of Benin.

I hope this proposal for the introduction of Mechatronics course in Republic of Benin will be helpful in the successful realization of this emerging engineering educational process.

Since Breedtronics is belong to the scope of our work, it will be studied in the future work by the designing a prototype of an intelligent poultry incubator multifunctional 


\section{ACKNOWLEDGEMENTS}

This research was possible due to the Scholarship provided by the Government of Republic of Benin, and given by the Ministry of Advanced Education and Scientific Research. I am grateful to, the Director of the Department of Scholarship, Doctor Galilou Abdoulaye and his staff for granting me the opportunity to continue learning Mechatronics Engineering at $\mathrm{PhD}$ level in China. Additionally I wish thank Doctor Adoko Amoussou Coffi for his inspiring advice during my $\mathrm{PhD}$ research as well as the Editor and the Reviewers for their support.

\section{REFERENCES}

[1]. M.Grimheden .Mechatronics Engineering Education. Doctoral Thesis in Machine Design, School of Industrial Engineering and Management, Royal Institute of Technology, Stockholm, Sweden.TRITA-MMK2006:01, ISSN1400-1179, ISBN91-7178-231-3(2006).

[2]. Kevin Craig. The Role of Computers in Mechatronics . Computing in Science and Engineering, 5,no. 2 (2003)80-85.

[3]. Devdas Shetty,Lou Manzione, and Ahad Ali. Survey of Mechatronic Techniques in Modern Machine Design. Journal of Robotics. Hindawi Publishing Corporation .Article ID932305.Volume 2012(2012) 9 pages .

[4]. A. Al-Habaibeh and R.M.Parkin. Low -Cost Mechatronic Systems for Teaching Condition Monitoring*.International Journal Engineering, 19, no.4 (2003)615-622

[5]. D.Shetty and R.Kolk. Mechatronic System Design . Thomson Engineering Publications, Toronto, Canada, (1998). [6]. K.Erkorkmaz and Y.Altintas. High Speed Contouring Control Algorithm for CNC Machine Tools . In Proceedings of the ASME International Mechanical Engineering Congress and Exposition, November (1998) pp. 463-469.

[7]. H. S. Cho and M. Y. Kim .Opto-mechatronics Technology: the characteristics and perspectives. IEEE Transactions on Industrial Electronics, 52, no.4 (2005)932943.

[8]. K. Kincade. Atomic-force microscopy finds new role in the nano world. Laser Focus World, 40, no.4 (2004)87-91.

[9]. N. Wakami, H. Nomura, and S. Araki. Fuzzy Logic for Home Appliances. in Fuzzy Logic and Neural Networks.McGraw- Hill, New York, NY, USA. C. H. Chen, Ed.(1996)pp21.1-21.23.

[10]. T. J. Krupa. Optical R\&D at The Army Research Laboratory. Optics and Photonics News, 11,no.6(200)16-25.

[11]. S. D. Robinson. MEMS Technology-Micro-machines Enabling the all Optical Network.in Proceedings of the 51st Electronic Components and Technology Conference.Orlando, Fla, USAJune(2001)423-428.

[12]. K. Tsuruta, Y.Mikuriya, and Y. Ishikawa. Micro Sensor Developments in Japan .Sensor Review,19, no.1(1999)37-42.

[13]. T. V. Higgins. Optical Storage Lights the Multimedia Future. Laser Focus World,31, no.9(1995)103.

[14]. S. G. Anderson. Smart Cars Take the High-Tech Road. Laser Focus World,32, no.6(1996)117.
[15]. T. G.McDonald and L. A.Yoder. Digital Micro Mirror Devices Make Projection Displays. Laser FocusWorld, 33, no.8 (1997)S5-S8.

[16]. A. Ali, Z. Chen, and J. Lee.Web-enabled Platform for distributed

and Dynamic Decision-making Systems. International Journal of Advanced Manufacturing Technology,38, no.1112(2008)1260-1270.

[17]. J. Lee. E-manufacturing-Fundamental, Tools, and Transformation.Robotics and Computer-Integrated Manufacturing,19,no. 6(2003)501-507.

[18]. Clarene W. de Silva. Mechatronic. S . An Integrated Approach .Library of Congress Cataloging- in- Publication Data CRC Press LLC. (2005).

[19]. Web site of Technological and Engineering in Columbia .Retrieve March 23, 2014 from:

http://www.itc.edu.co/en/university/undergraduate-

studies/mechatronics

[20]. Official web site: Government of Republic of Benin. Retrieve March 23, 2014 from: www.gouv.bj

[21]. Official web site: Univerity of Abomey-Calavi in Republic of Benin. Retrieve March 23, 2014 from: www.uac.bj

[22].http://www.uac.bj/public/index.php/en/university/mission s-and-visions

[23]. Professors Kevin C. Craig and Matthew A. Rosmarin. A Mechatronic System Design Project . Two Wheeled Balancing Transport Platform. Rensselaer Polytechnic Institute

Retrieve March 23, 2014 from: http://www.ni.com/whitepaper/4386/en/

\section{BIOGRAPHIE:}

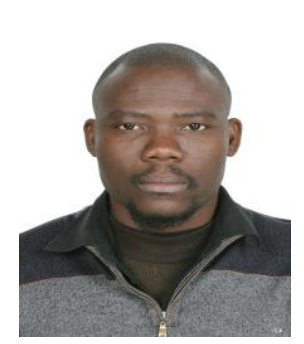

AKONDE L. D. Clément. Currently $\mathrm{PhD}$ Student in Mechatronics at School of Mechanical Science and Engineering .Huazhong University of Science and Technology (Wuhan-China).He received Master in Mechatronics at School of Mechanical Science and Engineering of Huazhong University of Science and Technology. Research fields: Mechanic of Robot and Mechanism of Robot Manipulators .Mathematics of Robot Manipulation 